\title{
A comparative study of Desarda's mesh free inguinal hernia repair with modified Bassini's repair
}

\author{
Hosni Mubarak Khan ${ }^{1}$, Tirumal Rao Patwari ${ }^{2 *}$ \\ ${ }^{1}$ AMBEDKAR MEDICAL COLLEGE \& HOSPITAL, DEPARTMENT OF GENERAL SURGERY, BANGALORE \\ ${ }^{2}$ KLE HOSPITAL, DEPARTMENT OF GENERAL SURGERY, BELAGAVI, KARNATAKA
}

Objective. This is a prospective study of 50 cases of inguinal hernias which were treated through open inguinal hernia repair techniques. The study was conducted with the objective of comparing the effectiveness of these procedures and complications. Materials and Methods. A number of 50 cases of inguinal hernias admitted to Dr. BR Ambedkar Medical College and Hospital were selected on the basis of the non-probability (purposive) sampling method. All the patients with direct and indirect uncomplicated hernias treated by means of an open approach were included. After the preoperative preparation, they were randomly chosen either for Desarda's or Modified Bassini's repair techniques. Results. In the postoperative period, moderate pain was experienced by 19 patients included in the Desarda group and 17 patients included in the Modified Bassini's repair group on day 1. The postoperative wound infection developed in 2 cases of Desarda and 3 cases of Modified Bassini's, erythema was observed in 2 cases of Desarda and 3 cases of Modified Bassini's, 3 cases reported the occurrence of seroma in the Desarda group and 4 cases of seroma were recorded in the Modified Bassini's group. Conclusions. The patients who underwent Desarda repair complained of a higher intensity of pain, which could probably be attributed to the extensive dissection involved. The duration of Desarda repair was longer due to the learning curve of the surgeons in our hospital. The return to normal gait and normal activities was significantly lower in the Desarda group. The duration of hospital stays and the postoperative complications was not significantly different in the two groups. There were no recurrences in either of the groups until the current study.
\end{abstract}

Category: Original Research Paper

Received: May 29, 2021

Accepted: July 24, 2021

Published: November 15, 2021

Keywords :

inguinal hernia, postoperative pain, return to normal activity, wound infection, recurrence

*

Corresponding author:

Tirumal Rao Patwari,

KLE Hospital, Department of General Surgery, Belagavi, Plot No. 345, Godse Nagar, Mandoli Road, Belagavi, Karnataka, 590006

E-mail: tiru_patwari@yahoo.com

\section{Introduction}

Worldwide, more than 20 million patients undergo inguinal hernia repair annually. The problem of our age is to find an operation that is simple, that does not require the implantation of a foreign body such as a mesh and that does not produce major complications during or after surgery.

For many years, the only quality criterion used after a hernia operation was the recurrence rate. Subsequently, the tension-free concept was developed and it is now used throughout the world. In recent years, the focus has increasingly shifted to possible chronic pain after hernia surgery. Based on these two criteria, the currently applicable "International Guidelines for Groin Hernia Management" published by the HerniaSurge Group recommend the use of mesh as a rule, either endoscopically via transabdominal preperitoneal or total extraperitoneal surgery or through open surgery, using the Lichtenstein technique [1].
However, newer studies have shown that the use of the Lichtenstein technique is possibly linked to a higher rate of postoperative pain [2]. The guidelines currently do not include alternative open surgical techniques, particularly mesh-free techniques, due to the small amount of scientific evidence. However, in recent years, numerous reports on postoperative pain after mesh implantation [3] and meshrelated complications [4] have led to increasing uncertainty among the patients. Moreover, studies that showed at least equally good results for the mesh-free procedures for selected patients have recently been reported $[5,6]$. Thus, the mesh-free procedures are currently regaining importance [7].

The Desarda technique is a newer surgical technique developed in India [8,9] which in the meantime should indeed be recognized as an alternative not only to the Shouldice technique, but also to the established, guidelinecompliant techniques. The first meta-analyses published in 
2017 and 2018 revealed results that are at least equally good with regard to the rates of recurrence and postoperative pain compared to the Lichtenstein technique $[10,11]$.

The learning curve for the Desarda technique appears to be shorter than that for the Shouldice technique due to the simplicity of the method. Mohan P. Desarda, the first to describe the eponymous technique, sees an indication for nearly every inguinal hernia. Based on our experience, this technique should be used primarily for smaller or mediumsized indirect as well as direct hernias and particularly for younger patients. However, in our opinion, it cannot be recommended in the event of general tissue weakness with a divided aponeurosis of the external oblique muscle. In any case, the transversal fascia should be split intraoperatively to effectively exclude a femoral hernia. For complex or combined hernias as well as for femoral hernias, the Desarda technique should not be used due to the expected weakness in the collagen tissue. A major advantage of open hernia surgery compared to endoscopic surgery is the option of intraoperative tailoring. With corresponding intraoperative findings, an anterior or posterior mesh technique can be used as a fallback.

The current work focuses on the long-term outcomes and confirms, even after 3 years, the results which are at least as good as those of the exhaustively studied Lichtenstein technique. This method, like the Lichtenstein technique, can be used in almost every setting, i.e., in the so-called "low-resource countries" as well. Moreover, particularly in "low-resource countries," the continuous availability of mesh is still not guaranteed today. The use of the so-called "low-cost meshes" [1] recommended in the current international guidelines has also been increasingly criticized in recent years in view of the product properties with regard to sterilization [12] and the European Medical Devices Regulation.

Another new aspect in the study is the evaluation of functionality after surgery. The Patient Global Impression of Change and the Prolo Scale are standardized instruments for measuring the patient's outcomes and they have been used since 2004 [13]. Here as well, this mesh-free procedure appears to have advantages particularly with regard to long-term outcomes.

The tailored concept recommended by the authors should be reviewed in additional differentiated comparative studies using the recognized European hernia classifications. At the same time, a clear binding standard for surgery with intraoperative exploration of all potential hernia gaps should be defined and the results reviewed as well as in large-scale register studies.

In view of the aforementioned results, the question remains as to what effect guidelines fundamentally have on health care services? The primary goal of guidelines is the standardization of preoperative preparation, surgical treatment, and aftercare of the patient in order to improve the quality of a surgical intervention across the board. The recommendations provided in guidelines reflect the external evidence, i.e., the results of the reliable scientific studies. Guidelines must never be hostile to innovation; however, as clearly noted in the guidelines of the HerniaSurge Group, they provide suggestions for further studies to review new or insufficiently investigated methods [1].

Furthermore, both regional and continental differences in particular must be taken into account. In addition, the possible industry influence on studies in which mesh-based procedures are extolled must not be ignored [14]. The fundamental recommendation of the HerniaSurge Group to use mesh-based procedures must therefore be very critically scrutinized.

Unfortunately, it is already clear today that there are hardly any qualified hernia surgeons who regularly offer their patients standardized, high-quality, and mesh-free surgical procedures. As a rule, the training program for every surgeon should include a suturing procedure, a meshbased open surgical technique, and a laparo-endoscopic technique.

The aim of this study is to evaluate the feasibility of the Desarda tissue repair at a tertiary Hospital as the treatment of primary inguinal hernia, by comparing it to the Modified Bassini's repair. The study period was 1 year including a 6-month follow up, in terms of operative time, postoperative pain, wound infection, erythema, seroma formation, return to normal activity, chronic pain, and early recurrence.

The purpose of this study is to compare short-term outcomes and recurrence rates for 6 months between the Desarda and the Modified Bassini's techniques.

The objectives of this study are:

1. To study the outcomes with respect to:

a) The operating time (incision to closure of the skin)

b) Post-operative pain

c) Return to normal activity

d) Seroma formation

e) The postoperative wound infection rate

f) Discharge time.

2. Recurrence rate

To look for any recurrence with regular follow-ups at one month, three months and six months, respectively.

\section{Materials and Methods}

Source of the data. The present study was conducted at Dr. BR Ambedkar Medical College and Hospital, Bangalore, between July 2018 and June 2019. The approval of the institutional ethical committee was obtained. The written informed consent was obtained from the participating patients. 
Research design. This is prospective comparative analysis which studies a total 50 consented patients from both genders, aged 18 years and above and diagnosed with inguinal hernia, out of which 25 patients were assigned the Desarda Repair, and the remaining 25 patients were assigned the Modified Bassini's Repair. The choice of surgery was given to the patient.

Sample size. Based on prevalence (1.7\% for all ages and $4 \%$ for above 45 -years of age) and life time risks, i.e., $27 \%$ for males and $3 \%$ for females, the sample size has been calculated. The short duration of study was also considered while calculating sample size.

A total of 50 patients were studied, out of which 5 underwent Desarda tissue repair and 25 underwent Modified Bassini's repair.

Inclusion criteria. All cases of inguinal hernia admitted for surgery.

1. The age group between 18yrs and 60yrs (including males and females).

2. With a primary, reducible inguinal or inguinalscrotal hernia; unilateral or bilateral or strangulated hernia.

3. ASA Grade I and II.

Exclusion criteria.

1. Old, debilitated patients with uncontrolled diabetes, hypertension, chronic steroid use, local skin infection (as they will be unable to give an accurate assessment of the key outcomes of the operation).

2. Recurrent Hernias.

3. Perioperative finding of separated, thin and/or weak external oblique aponeurosis.

4. Obstructive uropathy or chronic obstructive pulmonary disease, as they are associated with poor outcomes and high recurrence rates.

5. Collagen Vascular Disorders.

The time and duration of the study. One year including a 6-month follow-up period, from July 2018 to June 2019.

Operative technique. All the patients were visited on the day prior to surgery and were explained the procedure in detail and the written and informed consent was obtained. All the patients were kept nil orally (NPO) from 12 o'clock at mid night prior to the day of the surgery. The study was conducted on 50 patients. The patients were divided into two groups.

Statistical analysis. The student t test (two tailed, independent) was used to find the significance of the study parameters on a continuous scale between the two groups (Inter group analysis) on metric parameters. Leven`s test for homogeneity of variance was performed to assess the homogeneity of variance. The Chi-square/ Fisher Exact test was used to find the significance of the study parameters on categorical scale between two or more groups, the nonparametric setting for the Qualitative data analysis. Fisher Exact test are used when the cell samples are very small.
Significant figures

+ Suggestive significance ( $\mathrm{P}$ value: $0.05<\mathrm{P}<0.10)$

* Moderately significant (P value: $0.01<\mathrm{P}<0.05$ )

** Strongly significant ( $\mathrm{P}$ value: $\mathrm{P}<0.01)$

Statistical software. The Statistical software, namely SPSS 22.0, and R environment ver.3.2.2 were used for the analysis of the data and Microsoft word and Excel were used to generate graphs, tables etc.

\section{Results}

The age distribution of the studied patients is presented in Table 1 and Figure 1.

Table 1. The age distribution of the patients

\begin{tabular}{|l|c|c|c|}
\hline \multirow{2}{*}{$\begin{array}{c}\text { Age in } \\
\text { years }\end{array}$} & \multicolumn{2}{|c|}{ Surgery } & \multirow{2}{*}{ Total } \\
\cline { 1 - 4 } & Group D & Group M & \\
\hline$<20$ & $1(4 \%)$ & $0(0 \%)$ & $1(2 \%)$ \\
\hline $20-30$ & $2(8 \%)$ & $2(8 \%)$ & $4(8 \%)$ \\
\hline $31-40$ & $5(20 \%)$ & $4(16 \%)$ & $9(18 \%)$ \\
\hline $41-50$ & $7(28 \%)$ & $7(28 \%)$ & $14(28 \%)$ \\
\hline $51-60$ & $10(40 \%)$ & $12(48 \%)$ & $22(44 \%)$ \\
\hline Total & $25(100 \%)$ & $25(100 \%)$ & $50(100 \%)$ \\
\hline $\begin{array}{l}\text { Mean } \pm \\
\text { SD }\end{array}$ & $44.84 \pm 11.25$ & $47.44 \pm 10.15$ & $46.14 \pm 10.68$ \\
\hline
\end{tabular}

The samples are age-matched with $\mathrm{P}=0.395$, student t test

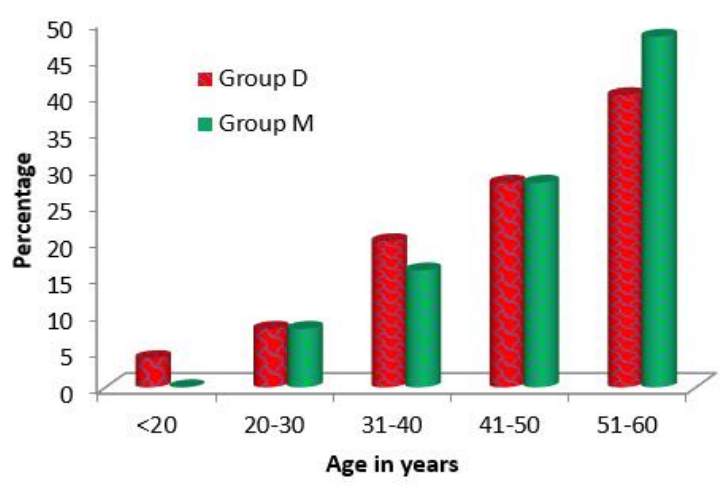

Figure 1. The age distribution of the patients

The gender distribution of the studied patients is presented in Table 2.

Table 2. The gender distribution of the patients studied

\begin{tabular}{|l|c|c|c|}
\hline \multirow{2}{*}{ Gender } & \multicolumn{2}{|c|}{ Surgery } & \multirow{2}{*}{ Total } \\
\cline { 2 - 3 } & Group D & Group M & \\
\hline Male & $25(100 \%)$ & $25(100 \%)$ & $50(100 \%)$ \\
\hline Total & $25(100 \%)$ & $25(100 \%)$ & $50(100 \%)$ \\
\hline \multicolumn{2}{|c|}{ P=1.000, Not Significant, Fisher Exact Test } \\
\hline
\end{tabular}


The diagnosis distribution of the patients in the two groups studied is presented in Table 3 and Figure 2.

Table 3. The diagnosis distribution of the patients in the two groups

\begin{tabular}{|l|c|c|c|}
\hline \multicolumn{1}{|c|}{ Diagnosis } & \multicolumn{2}{c|}{ Surgery } & Total \\
\cline { 2 - 4 } & Group D & Group M & \\
\hline $\begin{array}{l}\text { Right indirect } \\
\text { inguinal hernia }\end{array}$ & $12(48 \%)$ & $8(32 \%)$ & $20(40 \%)$ \\
\hline $\begin{array}{l}\text { Left indirect } \\
\text { inguinal hernia }\end{array}$ & $5(20 \%)$ & $6(24 \%)$ & $11(22 \%)$ \\
\hline $\begin{array}{l}\text { Right direct } \\
\text { inguinal hernia }\end{array}$ & $4(16 \%)$ & $6(24 \%)$ & $10(20 \%)$ \\
\hline $\begin{array}{l}\text { Left direct } \\
\text { inguinal hernia }\end{array}$ & $3(12 \%)$ & $2(8 \%)$ & $5(10 \%)$ \\
\hline $\begin{array}{l}\text { Bilateral direct } \\
\text { inguinal hernia }\end{array}$ & $1(4 \%)$ & $3(12 \%)$ & $4(8 \%)$ \\
\hline Total & $25(100 \%)$ & $25(100 \%)$ & $50(100 \%)$ \\
\hline
\end{tabular}

$\mathrm{P}=0.692$, Not Significant, Fisher Exact Test

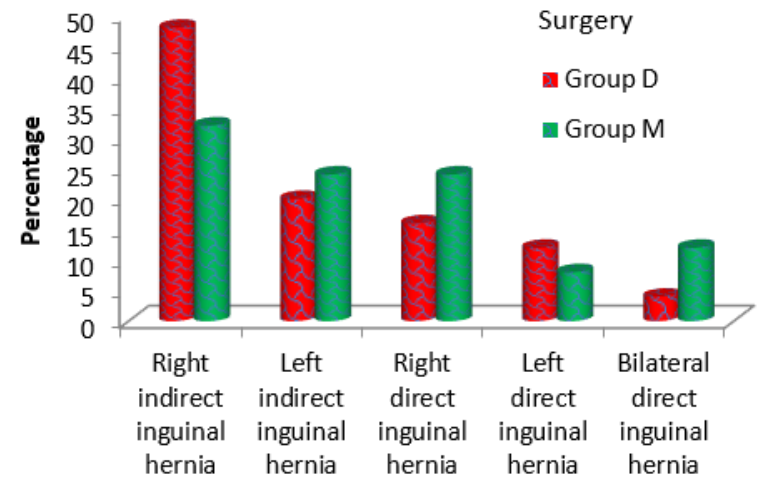

\section{Diagnosis}

Figure 2. The diagnosis distribution of the patients in the two groups studied

The operating time distribution of the patients in the two groups studied is presented in Table 4 and Figure 3.

Table 4. The operating time distribution of the patients in the two groups

\begin{tabular}{|l|c|c|c|}
\hline \multirow{2}{*}{$\begin{array}{c}\text { Operating } \\
\text { Time }\end{array}$} & \multicolumn{2}{|c|}{ Surgery } & \multirow{2}{*}{ Total } \\
\cline { 2 - 3 } & Group D & Group M & \\
\hline$<46$ & $0(0 \%)$ & $3(12 \%)$ & $3(6 \%)$ \\
\hline $46-52$ & $17(68 \%)$ & $22(88 \%)$ & $39(78 \%)$ \\
\hline$>52$ & $8(32 \%)$ & $0(0 \%)$ & $8(16 \%)$ \\
\hline Total & $25(100 \%)$ & $25(100 \%)$ & $50(100 \%)$ \\
\hline Mean \pm SD & $51.28 \pm 2.69$ & $48.60 \pm 2.53$ & $49.94 \pm 2.92$ \\
\hline \multicolumn{2}{|c|}{$\mathrm{P}=0.001 * *$, Significant, Student t test } \\
\hline
\end{tabular}

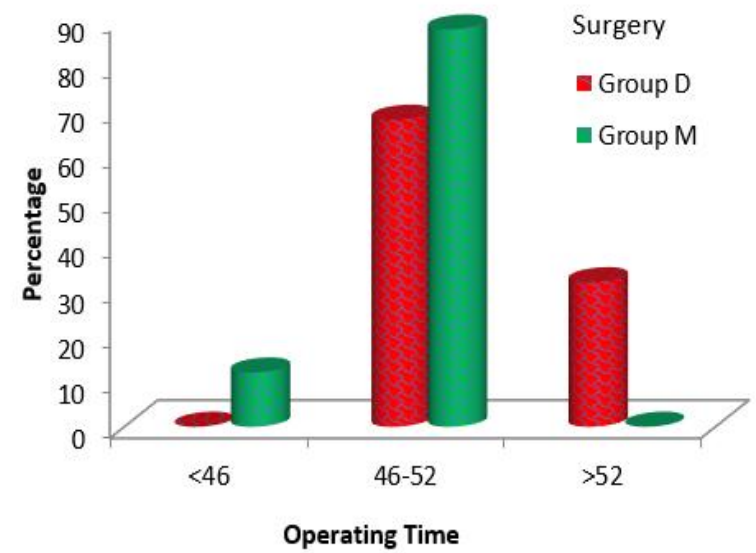

Figure 3. The operating time distribution of the patients in the two groups

The assessment of postoperative pain at different study points, and a comparison of postoperative pain between the two groups of patients studied are presented in Figures 4-a and 4-b, Tables 5 and 6, and Figures 5-a and 5-b.

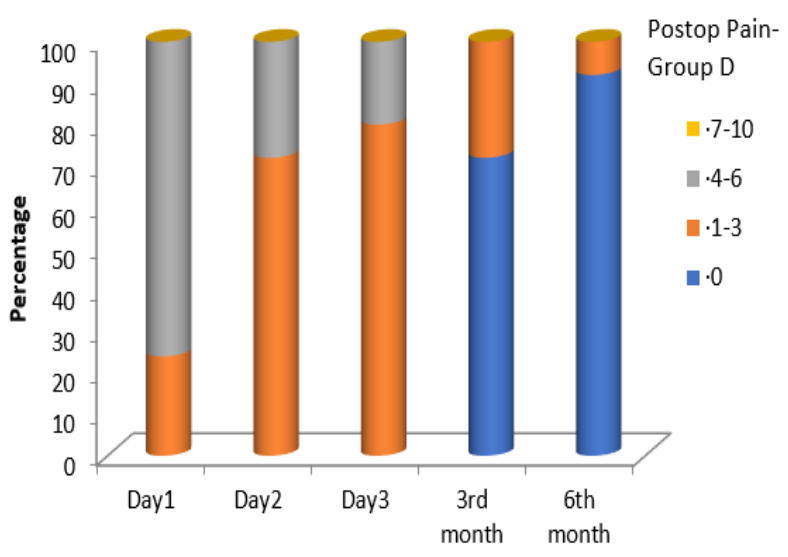

Figure 4 (a). Postoperative pain for group D

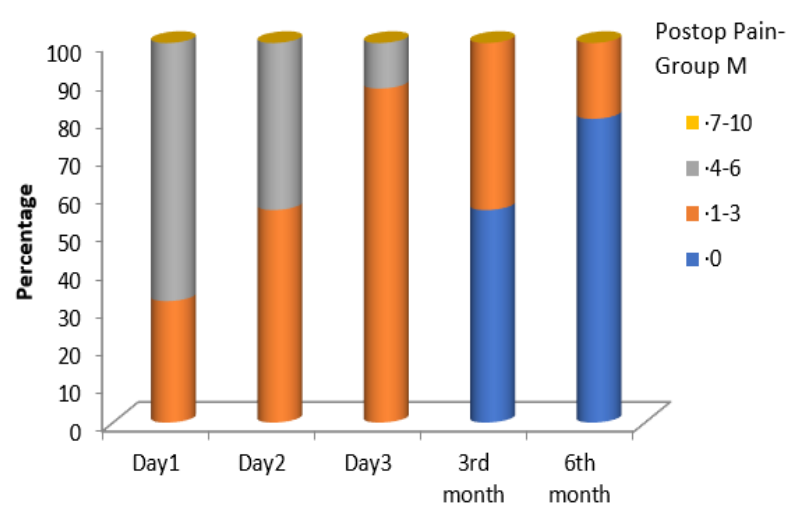

Figure 4 (b). Postoperative pain for group M 
Table 5. Postoperative pain; the assessment at different study points of the patients studied

\begin{tabular}{|c|c|c|c|c|c|c|}
\hline Postop Pain & Day1 & Day2 & Day3 & $3^{\text {rd }}$ month & $6^{\text {th }}$ month & $\%$ Difference \\
\hline \multicolumn{7}{|l|}{ Group D $(n=25)$} \\
\hline - 0 & $0(0 \%)$ & $0(0 \%)$ & $0(0 \%)$ & $18(72 \%)$ & $23(92 \%)$ & $92.0 \%$ \\
\hline - $1-3$ & $6(24 \%)$ & $18(72 \%)$ & $20(80 \%)$ & $7(28 \%)$ & $2(8 \%)$ & $-16.0 \%$ \\
\hline - $4-6$ & $19(76 \%)$ & $7(28 \%)$ & $5(20 \%)$ & $0(0 \%)$ & $0(0 \%)$ & $-76.0 \%$ \\
\hline - $7-10$ & $0(0 \%)$ & $0(0 \%)$ & $0(0 \%)$ & $0(0 \%)$ & $0(0 \%)$ & $0.0 \%$ \\
\hline \multicolumn{7}{|l|}{ Group M $(n=25)$} \\
\hline - 0 & $0(0 \%)$ & $0(0 \%)$ & $0(0 \%)$ & $14(56 \%)$ & $20(80 \%)$ & $80.0 \%$ \\
\hline - $1-3$ & $8(32 \%)$ & $14(56 \%)$ & $22(88 \%)$ & $11(44 \%)$ & $5(20 \%)$ & $-12.0 \%$ \\
\hline - $4-6$ & $17(68 \%)$ & $11(44 \%)$ & $3(12 \%)$ & $0(0 \%)$ & $0(0 \%)$ & $-68.0 \%$ \\
\hline - $7-10$ & $0(0 \%)$ & $0(0 \%)$ & $0(0 \%)$ & $0(0 \%)$ & $0(0 \%)$ & $0.0 \%$ \\
\hline$P$ value & 0.754 & 0.377 & 0.702 & 0.377 & 0.417 & - \\
\hline
\end{tabular}

Chi-Square/Fisher Exact Test

Table 6. Postoperative pain; a comparison between the two groups of patients

\begin{tabular}{|c|c|c|c|c|}
\hline \multirow{2}{*}{$\begin{array}{c}\text { Postop } \\
\text { Pain }\end{array}$} & \multicolumn{2}{|c|}{ Surgery } & Total & P value \\
\cline { 2 - 5 } & Group D & Group M & & \\
\hline Day1 & $4.2 \pm 0.97$ & $4.20 \pm 0.91$ & $4.20 \pm 1.04$ & 1.000 \\
\hline Day2 & $3.06 \pm 1.00$ & $3.00 \pm 1.04$ & $3.12 \pm 0.97$ & 0.675 \\
\hline Day3 & $2.64 \pm 0.83$ & $2.68 \pm 0.8$ & $2.60 \pm 0.87$ & 0.736 \\
\hline 3rd month & $0.36 \pm 0.48$ & $0.28 \pm 0.46$ & $0.44 \pm 0.51$ & 0.247 \\
\hline 6th month & $0.14 \pm 0.35$ & $0.08 \pm 0.28$ & $0.20 \pm 0.41$ & 0.230 \\
\hline
\end{tabular}

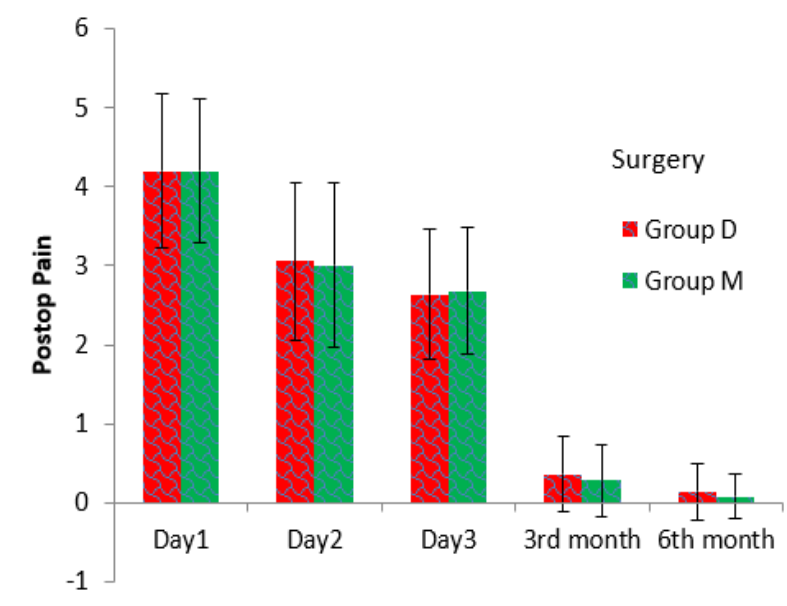

Figure 5 (a). Postoperative pain; a comparison between the groups

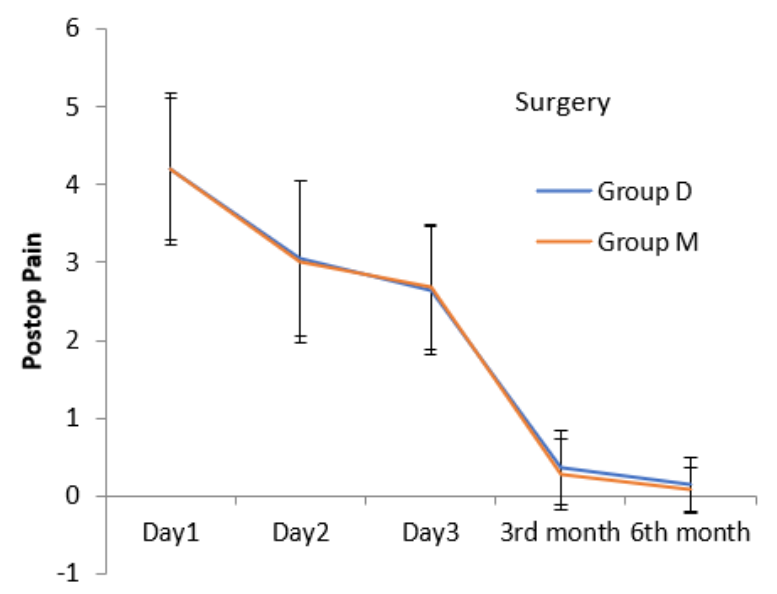

Figure 5 (b). Postoperative pain; a comparison between the groups

The distribution of ASA in the two groups studied is presented in Table 7 and Figure 6.

Table 7. The distribution of ASA in the two groups studied

\begin{tabular}{|l|c|c|c|}
\hline \multirow{2}{*}{ ASA } & \multicolumn{2}{|c|}{ Surgery } & \multirow{2}{*}{ Total } \\
\cline { 2 - 3 } & Group D & Group M & \\
\hline I & $7(28 \%)$ & $4(16 \%)$ & $11(22 \%)$ \\
\hline II & $18(72 \%)$ & $21(84 \%)$ & $39(78 \%)$ \\
\hline Total & $25(100 \%)$ & $25(100 \%)$ & $50(100 \%)$ \\
\hline
\end{tabular}

$\mathrm{P}=0.306$, Not Significant, Fisher Exact Test 


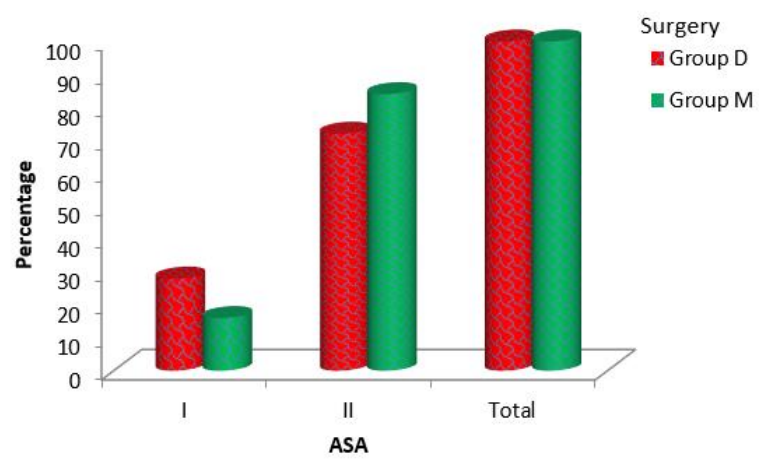

Figure 6. The distribution of ASA in the two groups studied

The return to normal gait of the patients in the two groups studied is presented in Table 8 and Figure 7.

Table 8. Return to normal gait: the distribution of the patients in the two groups

\begin{tabular}{|c|c|c|c|}
\hline $\begin{array}{c}\text { Return to } \\
\text { Normal } \\
\text { Gait }\end{array}$ & \multicolumn{2}{|c|}{ Surgery } & Total \\
\cline { 2 - 4 } & Group D & Group M & \\
\hline 1 & $2(8 \%)$ & $0(0 \%)$ & $2(4 \%)$ \\
\hline 2 & $9(36 \%)$ & $10(40 \%)$ & $19(38 \%)$ \\
\hline 3 & $14(56 \%)$ & $11(44 \%)$ & $25(50 \%)$ \\
\hline 4 & $0(0 \%)$ & $4(16 \%)$ & $4(8 \%)$ \\
\hline Total & $25(100 \%)$ & $25(100 \%)$ & $50(100 \%)$ \\
\hline Mean \pm SD & $2.48 \pm 0.65$ & $2.76 \pm 0.72$ & $2.62 \pm 0.69$ \\
\hline
\end{tabular}

$\mathrm{P}=0.092+$, Significant, Student $\mathrm{t}$ test

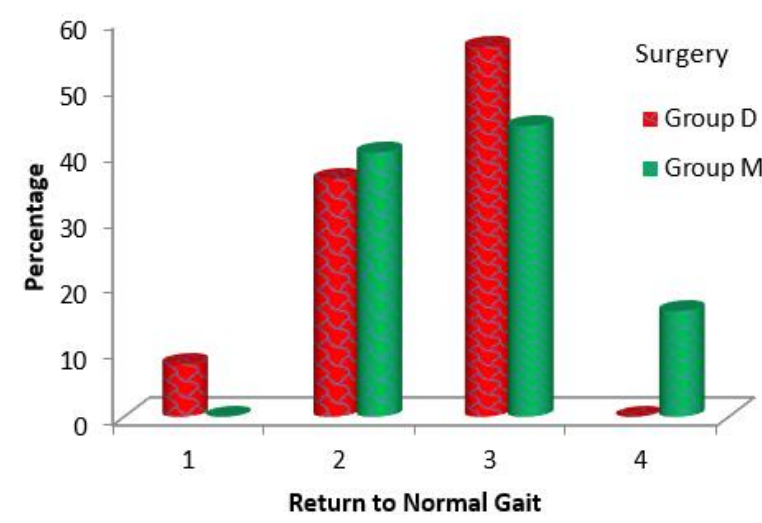

Figure 7. Return to normal gait: the distribution of the patients in the two groups

The distribution of patients' hospital stay in the two groups studied is presented in Table 9 and Figure 8.
Table 9. The distribution of patients' hospital stay in the two groups studied

\begin{tabular}{|l|c|c|c|}
\hline \multirow{2}{*}{$\begin{array}{c}\text { Hospital } \\
\text { Stay }\end{array}$} & \multicolumn{2}{|c|}{ Surgery } & \multirow{2}{*}{ Total } \\
\cline { 2 - 4 } & Group D & Group M & \\
\hline$<3$ & $6(24 \%)$ & $4(16 \%)$ & $10(20 \%)$ \\
\hline$>3$ & $19(76 \%)$ & $21(84 \%)$ & $40(80 \%)$ \\
\hline Total & $25(100 \%)$ & $25(100 \%)$ & $50(100 \%)$ \\
\hline
\end{tabular}

$\mathrm{P}=0.480$, Not Significant, Fisher Exact Test

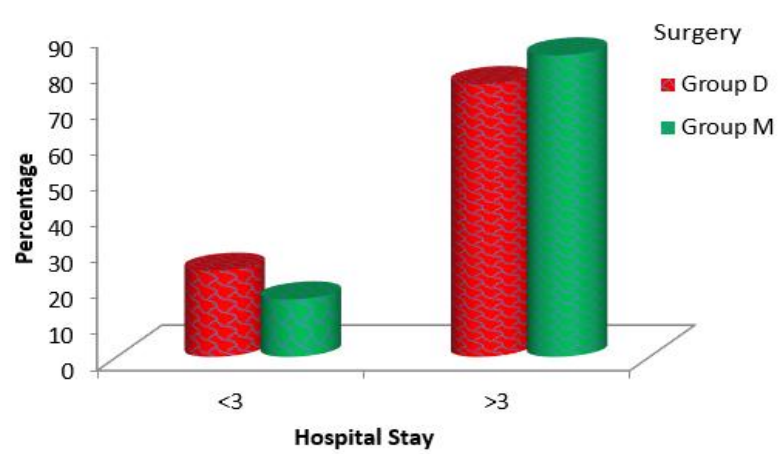

Figure 8. The distribution of patients' hospital stay in the two groups studied

The distribution of patients' complications in the two groups studied is presented in Table 10 and Figure 9.

Table 10. The distribution of patients' complications

\begin{tabular}{|c|c|c|c|c|}
\hline & \multicolumn{2}{|c|}{ Surgery } & \multirow{2}{*}{$\begin{array}{l}\text { Total } \\
(\mathbf{n}=\mathbf{5 0})\end{array}$} & \multirow[b]{2}{*}{ P value } \\
\hline & $\begin{array}{c}\text { Group D } \\
(\mathbf{n}=25)\end{array}$ & $\begin{array}{c}\text { Group M } \\
\quad(\mathbf{n}=\mathbf{2 5})\end{array}$ & & \\
\hline Erythema & $2(8 \%)$ & $3(12 \%)$ & $5(10 \%)$ & 1.000 \\
\hline Seroma & $3(12 \%)$ & $4(16 \%)$ & $7(14 \%)$ & 1.000 \\
\hline $\begin{array}{l}\text { Wound } \\
\text { Infection }\end{array}$ & $2(8 \%)$ & $3(12 \%)$ & $5(10 \%)$ & 1.000 \\
\hline
\end{tabular}

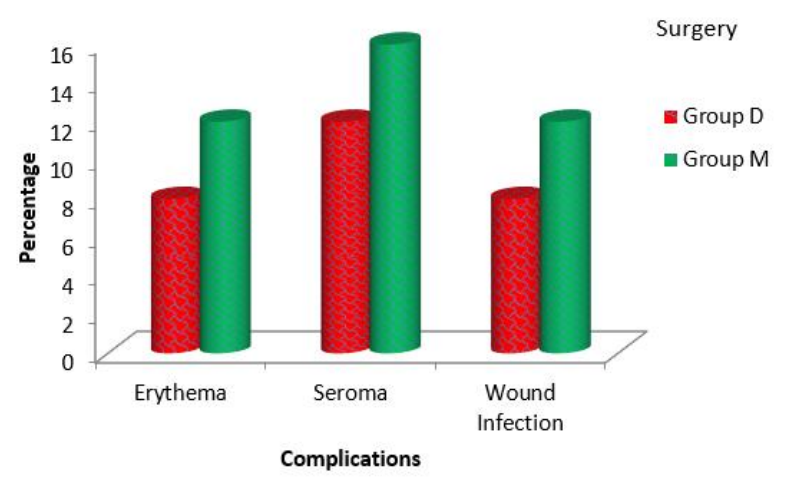

Figure 9. The distribution of patients' complications 
The RR distribution of the patients in the two groups studied is presented in Table 11 and Figure 10.

Table 11. The RR distribution of the patients in the two groups studied

\begin{tabular}{|c|c|c|c|c|}
\hline \multirow{2}{*}{$\mathbf{R R}$} & \multicolumn{2}{|c|}{ Surgery } & \multirow{2}{*}{$\begin{array}{c}\text { Total } \\
(n=50)\end{array}$} & \multirow[b]{2}{*}{$P$ value } \\
\hline & $\begin{array}{c}\text { Group D } \\
(\mathbf{n}=25)\end{array}$ & $\begin{array}{c}\text { Group M } \\
\qquad(\mathrm{n}=\mathbf{2 5})\end{array}$ & & \\
\hline $1 \mathrm{M}$ & $0(0 \%)$ & $0(0 \%)$ & $0(0 \%)$ & 1.000 \\
\hline $3 \mathrm{M}$ & $0(0 \%)$ & $0(0 \%)$ & $0(0 \%)$ & 1.000 \\
\hline $6 \mathrm{M}$ & $0(0 \%)$ & $0(0 \%)$ & $0(0 \%)$ & 1.000 \\
\hline
\end{tabular}

Chi-Square/Fisher Exact Test

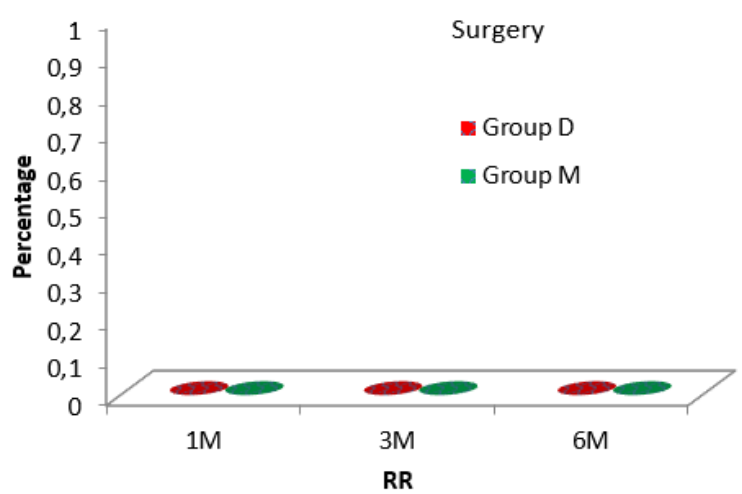

Figure 10. The RR distribution of the patients in the two groups studied

The return to normal activity (RNA) distribution of the patients in the two groups studied is presented in Table 12 and Figure 11.

Table 12. The return to normal activity (RNA) distribution of the patients in the two groups

\begin{tabular}{|l|c|c|c|}
\hline $\begin{array}{c}\text { Return } \\
\text { To } \\
\text { Normal } \\
\text { Activity }\end{array}$ & $\begin{array}{c}\text { Group D } \\
(\mathbf{n = 2 5})\end{array}$ & $\begin{array}{c}\text { Group M } \\
(\mathbf{n = 2 5})\end{array}$ & $\begin{array}{c}\text { Total } \\
(\mathbf{n = 5 0})\end{array}$ \\
\hline $1-3$ days & $2(8.0 \%)$ & 0 & $2(4.0 \%)$ \\
\hline $4-5$ days & $20(80.0 \%)$ & $13(52.0 \%)$ & $33(66.0 \%)$ \\
\hline 6-7 days & $3(12.0 \%)$ & $12(48.0 \%)$ & $15(30.0 \%)$ \\
\hline $\begin{array}{l}\text { Mean } \\
\pm \text { SD }\end{array}$ & $4.68 \pm 0.90$ & $5.24 \pm 1.01$ & $4.96 \pm 0.99$ \\
\hline \multicolumn{2}{|c|}{ P=0.044* , Significant, Student t test } \\
\hline
\end{tabular}

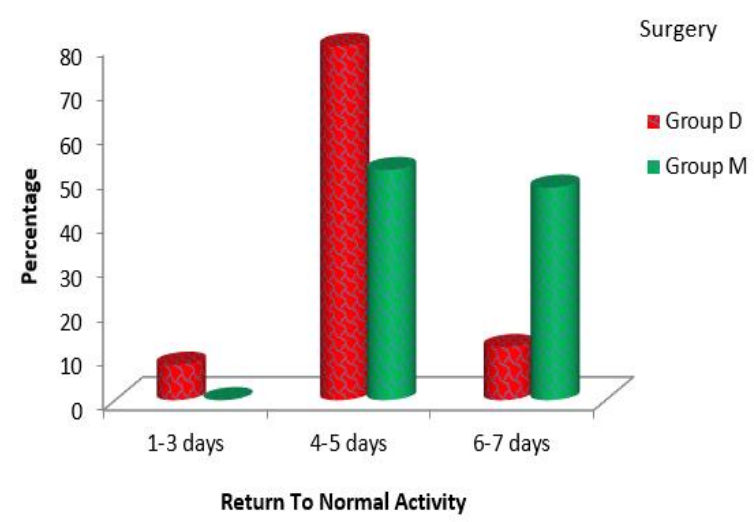

Figure 11. The return to normal activity (RNA) distribution of the patients in the two groups studied

Comparisons between the sex incidence, the age incidence and the types of hernia in the present study and the standard literature are presented in Tables 13-15.

Table 13. The comparison between the sex incidence in the present study and the standard literature

\begin{tabular}{|c|c|c|c|}
\hline Sex & Our Study & Ira M. Rutkow & Martin Kurzen \\
\hline Male & 50 & 90 & 97 \\
\hline Female & - & 10 & 3 \\
\hline
\end{tabular}

Table 14. The comparison between the age incidence in the present study and the standard literature

\begin{tabular}{|c|c|c|}
\hline $\begin{array}{c}\text { Age } \\
\text { (years) }\end{array}$ & $\begin{array}{c}\text { Present Study } \\
\text { (50 cases) }\end{array}$ & Ira M. Rutkow \\
\hline$<15$ & - & $18(18 \%)$ \\
\hline $15-44$ & $15(30 \%)$ & $26(26 \%)$ \\
\hline $45-64$ & $35(70 \%)$ & $30(30 \%)$ \\
\hline$>65$ & - & $26(26 \%)$ \\
\hline
\end{tabular}

Table 15. The comparison between the types of hernia in the present study and the standard literature data

\begin{tabular}{|c|c|c|}
\hline Type of hernia & $\begin{array}{c}\text { Present } \\
\text { Study (\%) }\end{array}$ & Ira M. Rutkow study \\
\hline Right- indirect & 40 & 36 \\
\hline Right- direct & 20 & 15 \\
\hline Left- indirect & 22 & 28 \\
\hline Left- direct & 10 & 13 \\
\hline Bilateral & 8 & 2 \\
\hline Total & 100 & 100 \\
\hline
\end{tabular}




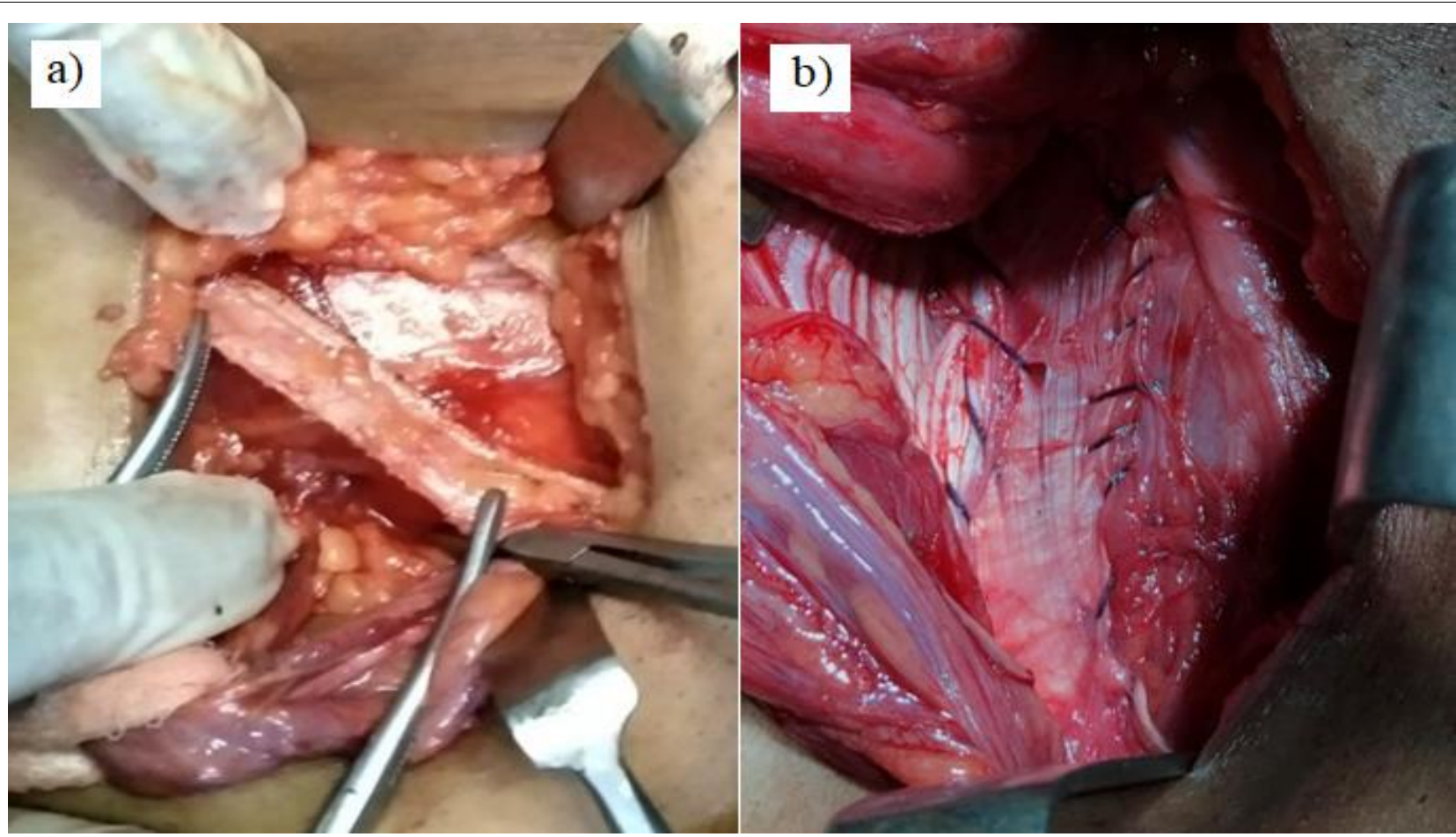

Figure $12(\mathbf{a}, \mathbf{b})$. The Desarda repair technique (the strip of EOA used to strengthen the posterior wall).

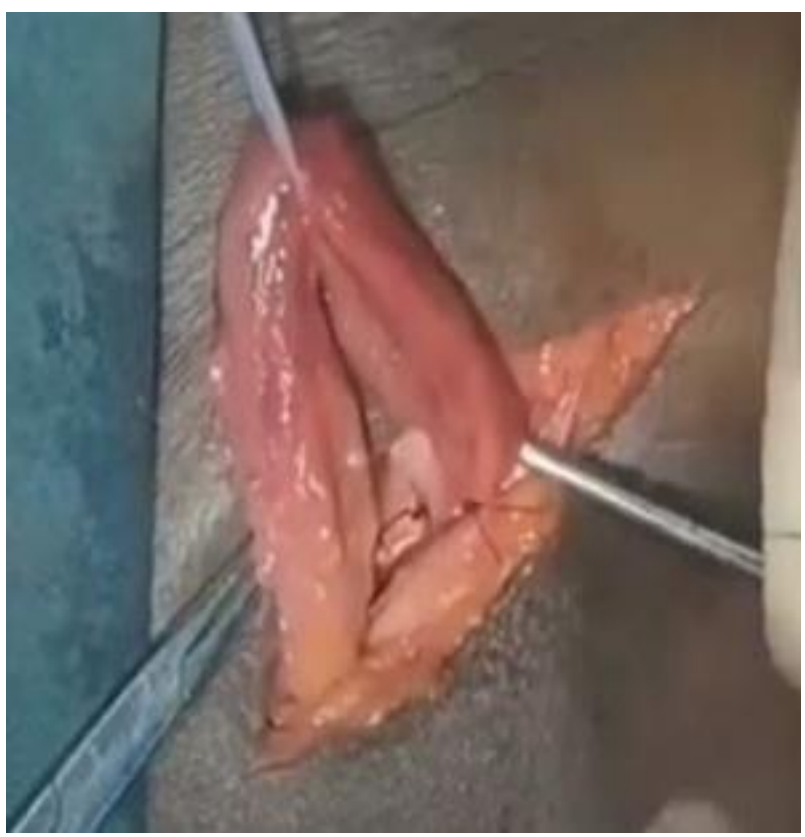

Figure 13. The modified Bassini’s repair technique.

\section{Discussion}

Inguinal hernias are by far the most common types of hernias [15]. The choice of a method depends on the surgeon; however, the ideal method for modern hernia surgery should be simple, cost effective, safe, tension free and permanent. The Lichtenstein operation achieves all these goals to a great extent $[16,17]$. The Lichtenstein mesh, however, has its shortcomings which include: its initial cost, the non-availability in many parts of the developing world, the tendency to fold and wrinkle, movement that may lead to mesh failure, since the groin is a very mobile area and chronic groin sepsis, that requires mesh removal [18].

The predictors of medium term and long-term outcomes are determined not only by the hernia characteristics, such as the presence of a bulge at the time of the operation and the size of the defect, but also by the short term post-operative pain and the length of time taken to resume work or ordinary chores [19]. Desarda has described a new method that seems to satisfy the abovementioned criteria and that does not require a prosthetic mesh nor does it use weakened muscles or transversalis fascia for repair (Figure 12). It is cost effective with low rates of complications $[20,21]$. This study was conducted to compare the short-term outcomes of the Modified Desarda's repair and Bassini's repair techniques (Figures 12 and 13) of inguinal hernias in Dr. B.R Ambedkar Medical College and Hospital.

The gender of the patients. Our study included 25 male patients included in both treatment groups. There was no female patient included in this study. In a study by Ira M. Rutkow, $90 \%$ of the total cases were male and $10 \%$ were female [22]. In a study by Martin Kurzer of British hernia center, 975 cases were male and 3\% were female [23].

The sex incidence in our study does not correlate with the other studies, it may be due to the shy nature of the Indian women who may not have come to us (Table 13).

The age of the patients. In a study by Ira M. Rutkow, the age at presentation is as follows [24]. It is compared with the present study. Our study included the population whose age ranged from 18 to 60 . It has been observed that within the $\mathrm{M}$ group, the minimum age of the patients is 23 years and the maximum age of the patients is 60 years. On 
the other hand, within the D group, the minimum age of the patients is 18 years and the maximum age of the patients is 59 years. Furthermore, it has been observed that the average age of the patients in the $\mathrm{M}$ group is 47.44 years $(\mathrm{SD}=10.15$ years $)$ and the average age of the patients in the $\mathrm{D}$ group is 44.84 years ( $\mathrm{SD}=11.25$ years). However, the t-test results indicate that this difference in the average age of the patients in the two treatment groups is statistically insignificant, $\mathrm{p}$-val $=0.395$ (Table 14).

In the study by Ira M. Rutkow, the highest incidence was in the age group 45-64, which included 30 cases and the next included 26 cases, both in the 15-44 and >65 age group. In our study, 15 cases were included in the 15- 44 age group and 35 cases in the 45-64 age group. The age incidence of our study matches the one in the abovementioned study.

The type of the hernia. The incidence of different types of hernia in our study is consistent with the analysis of the hernia centers 8-year series of 2,861 primary hernias (Table 15) [22].

The duration of surgery. All surgeries were done by a single surgeon and the time was considered between skin incision and skin close. It can be observed that the mean duration of surgery for the $\mathrm{D}$ group patients $(\mathrm{M}=51.28$, $\mathrm{SD}=2.69$ ) is high when compared to the mean duration of surgery for the $M$ group patients $(M=48.6, S D=2.53)$. Moreover, the independent samples t-test results show that this difference in the duration of surgery for the $\mathrm{M}$ group and the D group patients is statistically significant, pval $=0.001$.

Postoperative pain. Postoperative pain was accessed with VAS, ranging from 0 to 10, 0 to 3 being considered as Mild, 4-6 being considered as Moderate and 7-10 being considered as Severe pain. Choric pain or inguinodynia was accessed at the follow-up period at 14 days, 3 months and 6 months. It was observed that the post- operative pain pattern was similar in both groups.

The mean pain score for both groups was 4.2 on day 1 . The mean pain score in both groups was higher than that observed in a multivariate analysis comparing several methods by Lau and Lee [25]. However, they used post incision infiltration of macain, which we did not do in this study. They also gave a combination of oral Dextropropoxyphene $32.5 \mathrm{mg}$ and Voltaren suppositories $50 \mathrm{mg}$ to each patient compared to only $75 \mathrm{mg}$ of injectable Diclofenac given to each patient in this study. The combination treatment is more effective than monotherapy in pain management; however, it also increases the cost per patient.

The next pain assessment was done on the 2nd POD. The mean score for Desarda was slightly higher than that for Bassini's. The similarity in the pain values is most likely because both of them are tension methods, although Desarda theoretically provides less tension [26,27].
However, they differ from those reported by Desarda, who reported that 96 percent of his patients reported mild pain in the first 4 days and none experienced severe pain [26]. However, he did not state the extent of mild pain as per VAS he used, dosages of drugs and time of pain assessment. His mode of assessment of the pain was not clearly stated. Other comparative studies have found the pain index to be the highest with the Bassini's repairs as compared to the others [25].

Our findings in this study imply that the Desarda technique provides similar tension to that of Bassini's, if the amount of pain is equivalent to the tension in the suture lines, other factors being constant. The last pain assessment was done on the 6th month, when the patients returned for follow-up. Again, the patterns were similar for both groups. There was no statistically significant difference between the postoperative score and the method used for hernia repair on the 6 th month of follow-up.

This can be compared to Kyamanywa et al [28], who found the mean pain for Bassini's on the 7th POD to be 2.8. This is also in agreement with what Lau and Lee reported [25], i.e., that postoperative pain in herniorraphy was not affected by the method used on the 7th and 14th POD. Using Pearsons' correlation coefficient, there was no statistically significant correlation between the postoperative pain score and the operation group 24 hours postoperatively, on the $2 \mathrm{nd}$, the $3 \mathrm{rd}$ POD and the $3 \mathrm{rd}$ or the 6 th month. These findings are in agreement with the previous comparative studies [28-30].

Return to normal activity. In our study, we noticed that the mean time to return to normal activities was 4.68 days in the Desarda group as compared to 5.24 days in the Modified Bassini's group, and it was significant with $\mathrm{p}$ val $=0.044$.

In this study, all the patients had resumed their normal gait by the 5th POD. The mode was also determined as the mean may be influenced by the extremes on both ends. The mode of both groups was on the 3rd POD. The mean day in the resumption of normal gait was lesser in the Desarda group compared to the Modified Bassini's group, which when compared to the findings by Kyamanywa et al. [28], who compared the Lichtenstein mesh repair to the modified Bassini's and showed similar mean return of normal activities. The difference between the two methods regarding the day of resuming the normal gait is because both methods are tension methods, but Desarda's technique theoretically provides less tension. Other randomized studies have to be conducted to verify this hypothesis.

Gait assessment, although less specific, is an activity done by the patient. Other studies that have used activities such as bathing, dressing and walking around the house have shown that the majority of the patients could do all these activities by the 4th POD30. 
Postoperative complications. In our study we observed that the postoperative complications were similar in both groups and that there was no recurrence in either of the groups studied until the present date.

The external oblique muscle technique meets all the criteria of modern hernia surgery. Desarda's technique is simple and easy to perform. It does not require risky nor complicated dissection. There is no tension in the suture line. It does not require any foreign material and does not use weak muscle or fascia transversalis for repair. It does not use mesh prosthesis, thus being more economical and it also avoids the morbidity associated with foreign bodies, such as rejection, infection, chronic groin pain. In their randomized controlled trial, Szopinski et al. stated that the Desarda's technique has the potential of enlarging the number of tissue-based methods available to treat groin hernias [31]. The most obvious indications for use are financial constraints or the patient's disapproval in using a mesh.

\section{Conclusions}

The present study is a comparative study between the Desarda's Mesh-free Inguinal Hernia repair and the Modified Bassini's repair. The study was conducted with an intension of comparing the effectiveness of various surgeries and their complications, if any.

All the patients were intensively monitored in the immediate postoperative period and the complications were noted. We found that fewer patients experienced moderate pain in the Modified Bassini's compared to the Desarda's group. However, we found that the return to normal gait and activities was lesser in the Desarda's group, which was very significant. There was no marked difference in the postoperative complications between the two groups.

The patients were followed-up in the postoperative period for variable durations and no recurrences were reported until the present date in either of the groups.

There were few limitations to the study, including smaller sample size and shorter duration of study, so the long-term outcomes and results cannot be assessed and, thus the follow-up continues for these patients.

To summarize, there is no universal repair method for groin hernias, and all surgeons will agree to that. The availability of such an array of surgical techniques in the treatment of groin hernias is bound to confuse the young surgeon. All techniques will have hard proponents, as well as opponents. This is where the practice of evidence-based medicine is very crucial and one should have close watch on the long-term follow-up results of any particular newer procedures. Until then, one may practice a time-efficient and a good surgical technique, which has the least recurrence rate and which is handed over to them by their seniors, taking into account the cost factor, which is still important in developing countries like ours and with the noble thought that the patient is the most important.

\author{
Abbreviations \\ BP : Blood pressure \\ BPH : Benign Prostatic Hypertrophy \\ COPD : Chronic Obstructive Pulmonary Disease \\ DM : Diabetes Mellitus \\ ECG : Electrocardiogram \\ $\mathrm{F} \quad$ : Frequency \\ $\mathrm{Hb}$ : Hemoglobin \\ HBsAg : Hepatitis B Antigen \\ HIV : Human Immuno-Deficiency Virus \\ HTN : Hypertension \\ IHD : Ischemic heart disease \\ NICE : National Institute of Clinical Excellence \\ NS : Not significant \\ P : Probability \\ PR : Pulse Rate \\ RBS : Random Blood Sugar \\ $\mathrm{p} \quad$ : P-value \\ TB : Tuberculosis \\ IEV : Inferior epigastric vessels \\ MMP : Matrix Mettaloproteinase \\ EOA : External Oblique Aponeurosis
}

\section{Conflict of interest disclosure}

There are no known conflicts of interest in the publication of this article. The manuscript was read and approved by all authors. The study is self-sponsored with support from the institution. There is no commercial or conflict of interests.

\section{Compliance with ethical standards}

Any aspect of the work covered in this manuscript has been conducted with the ethical approval of all relevant bodies and that such approvals are acknowledged within the manuscript.

The approval of the institutional ethical committee was obtained. The written informed consent was obtained from the participating patients.

The following ethical guidelines were taken into consideration for the research period: the dignity and wellbeing of the patient was protected at all times, the research data remained confidential throughout the study, the research protocol was presented to the Institutional Ethical Review Board and due permission was obtained to undertake the study.

\section{Acknowledgement}

Dr. K. P. Suresh, Scientist (Biostatistics), The National Institute of Veterinary Epidemiology and Disease Informatics (NIVEDI), Bangalore-560024 


\section{References}

1. HerniaSurge Group. International guidelines for groin hernia management. Hernia. 2018 Feb;22(1):1-165. doi: 10.1007/s10029-017-1668-x

2. Miserez M, Peeters E, Aufenacker T, Bouillot JL, Campanelli G, Conze J, Fortelny R, Heikkinen T, Jorgensen LN, Kukleta J, Morales-Conde S, Nordin P, Schumpelick V, Smedberg S, Smietanski M, Weber G, Simons MP. Update with level 1 studies of the European Hernia Society guidelines on the treatment of inguinal hernia in adult patients. Hernia. 2014 Apr;18(2):151-63. doi: 10.1007/s10029-014-1236-6

3. Fischer JE. Hernia repair: why do we continue to perform mesh repair in the face of the human toll of inguinodynia? Am J Surg. 2013 Oct;206(4):619-23. doi: 10.1016/j.amjsurg.2013.03.010

4. Iakovlev V, Koch A, Petersen K, Morrison J, Grischkan D, Oprea V, Bendavid R. A Pathology of Mesh and Time: Dysejaculation, Sexual Pain, and Orchialgia Resulting From Polypropylene Mesh Erosion Into the Spermatic Cord. Ann Surg. 2018 Mar;267(3):569-575. doi: 10.1097/SLA.0000000000002134

5. Malik A, Bell CM, Stukel TA, Urbach DR. Recurrence of inguinal hernias repaired in a large hernia surgical specialty hospital and general hospitals in Ontario, Canada. Can J Surg. 2016 Feb;59(1):19-25. doi: 10.1503/cjs.003915

6. Köckerling F, Koch A, Adolf D, Keller T, Lorenz R, Fortelny RH, Schug-Pass C. Has Shouldice Repair in a Selected Group of Patients with Inguinal Hernia Comparable Results to Lichtenstein, TEP and TAPP Techniques? World J Surg. 2018 Jul;42(7):2001-2010. doi: 10.1007/s00268-017-4433-5

7. Lorenz R. Do we really need a renaissance of pure tissue repair? Invited comment to: Desarda's technique versus Lichtenstein technique for the treatment of primary inguinal hernia: a systematic review and metaanalysis of randomized controlled trials. Emile S, Elfeki H. Hernia. 2018 Jun;22(3):397-398. doi: 10.1007/s10029-018-1742-z

8. Desarda MP. New method of inguinal hernia repair: a new solution. ANZ J Surg. 2001 Apr;71(4):241-4. doi: 10.1046/j.1440-1622.2001.02092.x

9. Desarda MP. No-mesh inguinal hernia repair with continuous absorbable sutures: a dream or reality? (A study of 229 patients). Saudi J Gastroenterol. 2008 Jul;14(3):122-7. doi: 10.4103/1319-3767.41730

10. Emile SH, Elfeki H. Desarda's technique versus Lichtenstein technique for the treatment of primary inguinal hernia: a systematic review and meta-analysis of randomized controlled trials. Hernia. 2018 Jun;22(3):385-395. doi: 10.1007/s10029-017-1666-z
11. Ge H, Liang C, Xu Y, Ren S, Wu J. Desarda versus Lichtenstein technique for the treatment of primary inguinal hernia: A systematic review. Int J Surg. 2018 Feb;50:22-27. doi: 10.1016/j.ijsu.2017.11.055

12. Mitura K, Kozieł S. The influence of different sterilization types on mosquito net mesh characteristics in groin hernia repair. Hernia. 2018 Jun;22(3):483-490. doi: 10.1007/s10029-018-1756-6

13. Hurst H, Bolton J. Assessing the clinical significance of change scores recorded on subjective outcome measures. J Manipulative Physiol Ther. 2004 Jan;27(1):26-35. doi: 10.1016/j.jmpt.2003.11.003

14. Probst P, Grummich K, Ulrich A, Büchler MW, Knebel $\mathrm{P}$, Diener MK. Association of industry sponsorship and positive outcome in randomised controlled trials in general and abdominal surgery: protocol for a systematic review and empirical study. Syst Rev. 2014 Nov 27;3:138. doi: 10.1186/2046-4053-3-138

15. Patil SM, Gurujala A, Kumar A, Kumar KS, Mithun G. Lichtenstein Mesh Repair (LMR) v/s Modified Bassini's Repair (MBR) + Lichtenstein Mesh Repair of Direct Inguinal Hernias in Rural Population - A Comparative Study. J Clin Diagn Res. 2016 Feb;10(2): PC12-5. doi: 10.7860/JCDR/2016/15368.7292

16. Shulman AG, Amid PK, Lichtenstein IL. The safety of mesh repair for primary inguinal hernias: results of 3,019 operations from five diverse surgical sources. $\mathrm{Am}$ Surg. 1992 Apr;58(4):255-7.

17. Awad SS, Fagan SP. Current approaches to inguinal hernia repair. Am J Surg. 2004 Dec;188(6A Suppl):9S16S. doi: 10.1016/j.amjsurg.2004.09.007

18. Taylor SG, O'Dwyer PJ. Chronic groin sepsis following tension-free inguinal hernioplasty. Br J Surg. 1999; 86(4):562-5. doi: 10.1046/j.1365-2168.1999.01072.x

19. Cunningham J, Temple WJ, Mitchell P, Nixon JA, Preshaw RM, Hagen NA. Cooperative hernia study. Pain in the postrepair patient. Ann Surg. 1996;224(5): 598-602. doi: 10.1097/00000658-199611000-00003

20. Desarda MP. Surgical physiology of inguinal hernia repair--a study of 200 cases. BMC Surg. 2003 Apr 16;3:2. doi: 10.1186/1471-2482-3-2

21. Desarda MP. Physiological repair of inguinal hernia: a new technique (study of 860 patients). Hernia. 2006 Apr;10(2):143-6. doi: 10.1007/s10029-005-0039-1

22. Rutkow IM. Epidemiologic, economic, and sociologic aspects of hernia surgery in the United States in the 1990s. Surg Clin North Am. 1998 Dec;78(6):941-51, vvi. doi: 10.1016/S0039-6109(05)70363-7

23. Kurzer M, Belsham PA, Kark AE. The Lichtenstein repair. Surg Clin North Am. 1998 Dec;78(6):1025-46. doi: 10.1016/S0039-6109(05)70367-4

24. Rutkow IM, Robbins AW. Demographic, classificatory, and socioeconomic aspects of hernia repair in the United 
States. Surg Clin North Am. 1993 Jun;73(3):413-26. doi: 10.1016/s0039-6109(16)46027-5

25. Lau H, Lee F. Determinant factors of pain after ambulatory inguinal herniorrhaphy: a multi-variate analysis. Hernia. 2001 Mar;5(1):17-20. doi: 10.1007/BF01576159

26. Andresen K. Onstep repair of inguinal hernias. Dan Med J. 2018 Mar;65(3):B5467.

27. Amato G, Romano G, Agrusa A, Cocorullo G, Gulotta $\mathrm{G}$, Goetze T. Dynamic inguinal hernia repair with a $3 \mathrm{~d}$ fixation-free and motion-compliant implant: a clinical study. Surg Technol Int. 2014 Mar;24:155-65.

28. Paul A, Troidl H, Williams JI, Rixen D, Langen R. Randomized trial of modified Bassini versus Shouldice inguinal hernia repair. The Cologne Hernia Study Group. Br J Surg. 1994 Oct;81(10):1531-4. doi: 10.1002/bjs. 1800811045
29. Mohamedahmed AYY, Ahmad H, Abdelmabod AAN, Sillah AK. Non-mesh Desarda Technique Versus Standard Mesh-Based Lichtenstein Technique for Inguinal Hernia Repair: A Systematic Review and Meta-analysis. World J Surg. 2020 Oct;44(10):33123321. doi: 10.1007/s00268-020-05587-y

30. Kuhry E, van Veen RN, Langeveld HR, Steyerberg EW, Jeekel J, Bonjer HJ. Open or endoscopic total extraperitoneal inguinal hernia repair? A systematic review. Surg Endosc. 2007 Feb;21(2):161-6. doi: 10.1007/s00464-006-0167-4

31. Szopinski J, Dabrowiecki S, Pierscinski S, Jackowski M, Jaworski M, Szuflet Z. Desarda versus Lichtenstein technique for primary inguinal hernia treatment: 3-year results of a randomized clinical trial. World J Surg. 2012 May;36(5):984-92. doi: 10.1007/s00268-0121508-1 